\title{
GAMBARAN PENGETAHUAN IBU HAMIL TENTANG PERUBAHAN PSIKOLOGIS SELAMA KEHAMILAN
}

\author{
Description Of Knowledge Of Pregnant Women About Changes Psychological \\ During Pregnancy
}

Ajeng Novita Sari ${ }^{1}$, Danik Riawati ${ }^{2}$

STIKES Mamba'ul 'Ulum Surakarta

( Ajengnovitasari@stikesmus.ac.id)

\begin{abstract}
ABSTRAK
Latar Belakang : Berdasarkan hasil data WHO, terdapat 352 orang dari 2,321 ibu hamil primigravida yang mengeluh rasa takut $36 \%$, cemas $42 \%$, tidak percaya diri 22\% pada saat kehamilan. Data ini juga didukung oleh hasil Survey Demografi Kesehatan Indonesia (SDKI), terdapat 50 orang dari $850 \mathrm{ibu}$ hamil primigravida yang mengeluh stress $20 \%$, cemas $35 \%$ dan takut $45 \%$ pada kehamilan. Sedangkan menurut Depkes Medan tahun 2009, terdapat 25 orang dari 100 ibu hamil yang mengeluh cemas $70 \%$, takut $25 \%$, dan stres $5 \%$.

Tujuan : Penelitian ini bertujuan untuk mengetahui pengetahuan Ibu Hamil Tentang Perubahan Psikologis Selama Kehamilan di Praktik Mandiri Bidan Dyah Sugiyanto Sukoharjo tahun 2019.

Metode : Jenis penelitian ini adalah deskriptif kuantitatif dengan pendekatan cross sectional. Lokasi penelitian di Praktik Mandiri Bidan (PMB) Dyah Sugiyanto Sukoharjo. Sampel penelitian menggunakan teknik accidental sampling. Sampel dalam penelitian ini yaitu ibu hamil yang berkunjung di PMB Dyah Sugiyanto sejumlah 36 ibu hamil. Pada penelitian ini menggunakan alat pengumpul data berupa kuesioner, jenis kuesioner dalam penelitian ini adalah kuesioner tertutup sedangkan untuk analisis data menggunakan distribusi frekuensi.

Hasil : Pengetahuan ibu hamil mengenai perubahan psikologis selama kehamilan mayoritas dalam kategori cukup yaitu 29 responden $(80,55 \%)$. mayoritas ibu hamil berumur 21-25 tahun sebanyak 11 responden (30,55\%), berpendidikan SMP sebanyak 14 responden $(38,88 \%)$, dan pekerjaan swasta sebanyak 13 responden $(36,11 \%)$.
\end{abstract}

Simpulan : Penelitian ini menunjukan bahwa pengetahuan ibu hamil tentang perubahan psikologis selama kehamilan mayoritas berpengetahuan cukup.

Kata kunci : pengetahuan, kehamilan, perubahan psikologis selama kehamilan.

\section{ABSTRACT}

Background: Based on the results of WHO data, there were 352 people from 2,321 primigravida pregnant women who complained of fear $36 \%$, anxious $42 \%$, not confident $22 \%$ during pregnancy. This data is also supported by the results of the Indonesian Health Demographic Survey (IDHS), there were 50 people from 
850 primigravida pregnant women who complained of $20 \%$ stress, $35 \%$ anxious and $45 \%$ afraid of pregnancy. Whereas according to the Ministry of Health in Medan in 2009, there were 25 people out of 100 pregnant women who complained about $70 \%$ anxiety, $25 \%$ fear, and $5 \%$ stress.

The Aim: This study aims to determine the knowledge of pregnant women about psychological changes during pregnancy at BPM Dyah Sugiyanto Sukoharjon in 2019.

Method: this type of research is descriptive analytic with cross sectional approach. Research location at PMB Dyah Sugiyanto Sukoharjo. The research sample used accidental sampling technique. The sample in this study were 36 pregnant women who visited PMB Dyah Sugiyanto. In this study using a data collection tool in the form of a questionnaire, the type of questionnaire in this study was a closed questionnaire while for data analysis using frequency distribution.

Results: The knowledge of pregnant women regarding psychological changes during pregnancy was mostly in the adequate category, namely 29 pregnant women (80.55\%). the majority of pregnant women aged 21-25 years were 11 respondents (30.55\%), junior high school educated as many as 14 respondents (38.88\%), and private jobs as many as 13 respondents (36.11\%).

Conclusion: shows that the knowledge of pregnant women about psychological changes during pregnancy is largely knowledgeable.

Keywords: knowledge, pregnancy, psychological changes during pregnancy.

\section{PENDAHULUAN}

Kehamilan merupakan peristiwa penting bagi seorang wanita, kesehatan wanita sangat di tentukan oleh kesehatan jiwanya. Wanita lebih bereaksi terhadap setiap kondisi yang di hadapinya selama kehamilan di bandingkan dengan pria. Oleh karena itu kematangan perkembangan emosional dan psikoseksual sangat di perlukan oleh seseorang yang berkeinginan untuk mempunyai anak. (Kusmiyati,dkk, 2008).

Pada dasarnya ibu yang mengalami kehamilan dituntut tidak hanya siap secara psikologis, tetapi juga siap secara mental. Perubahan secara fisik mudah ditebak namun perubahan secara psikologis sangat sulit ditebak dan tidak selalu sama pada setiap ibu ataupun pada setiap kehamilan. Walaupun kehamilan adalah suatu proses yang normal akan tetapi kebanyakan wanita akan mengalami perubahan baik dari segi psikologis maupun emosional selama kehamilan. Sering kali kita mendengar betapa bahagianya dia karena akan menjadi seorang ibu tetapi tidak jarang ada wanita yang merasa khawatirkalau terjadi masalah selama kehamilannya misalnya ibu takut dengan anak yang akan dilahirkannya apakah normal ataukah tidak atau mungkin ibu takut kehilangan kecantikannya. (Purwanto, 2011).

Berdasarkan hasil data WHO, terdapat 352 orang dari 2,321 ibu hamil primigravida yang mengeluh rasa takut $36 \%$, cemas $42 \%$, tidak percaya diri $22 \%$ 
pada saat kehamilan. Data ini juga didukung oleh hasil Survey Demografi Kesehatan Indonesia (SDKI), terdapat 50 orang dari $850 \mathrm{ibu}$ hamil primigravida yang mengeluh stress $20 \%$, cemas $35 \%$ dan takut $45 \%$ pada kehamilan. Sedangkan menurut Depkes Medan tahun 2009, terdapat 25 orang dari $100 \mathrm{ibu}$ hamil yang mengeluh cemas $70 \%$, takut $25 \%$, dan stres $5 \%$. Salah satu yang hal yang dapat Lisa Rahmawati, dkk, dilakukan agar ibu memahami perubahan psikologis yang terjadi yaitu dengan cara pemeriksaan antenatal care. Adapun dampak psikologis pada ibu hamil di antaranya sensitif, cenderung malas, minta perhatian lebih, gampang cemburu, dan ansietas (kecemasan). Wanita hamil akan lebih terbuka terhadap dirinya sendiri dan suka berbagi pengalaman kepada orang lain. Ibu hamil akan merenungkan segala impiannya, angan-anganya, fantasinya terhadap objek-objek, peristiwa, atau konsep abstrak, seperti kematian, kehidupan, keberhasilan dan kebahagiaan selama hamil.(Yuliatun, 2011)

Sebagian besar ibu hamil gembira karena telah dapat menyesuaikan diri dengan rencana membentuk hidup baru. Karena tubuh dan emosi seluruhnya berhubungan, perubahan fisik dapat mempengaruhi emosi. Maka efek atau gejala melihat dalam pikiran dan energinya yang lebih konstruktif. Calon ibu tidak merasa sehat benar dan umumnya mengalami depresi. Calon bapak mungkin ada yang memandang wanita hamil dengan kekaguman dan menghindari hubungan seksual karena takut melukai bayinya. Jumlah keinginan ibu hamil dalam hal ini dapat dicontohkan kasus seorang ibu G1P0A0 nama Ny L, umur 25 tahun datang ke klinik untuk memeriksakan kehamilannya. Dalam kondisi hamil ada gejala psikologis yang ibu tersebut merasakan merasa takut, khawatir, dan gelisah ditambah suaminya tidak lagi perduli pada dirinya. (Arisnawati, 2013).

Dari hasil studi pendahuluan di BPM Dyah Sugiyanto pada tanggal 12 Januari 2019, dari wawancara tidak tersetruktur pada 10 ibu hamil didapatkan hasil bahwa $7 \mathrm{ibu}$ hamil tidak mengetahui tentang perubahan psikologis selama kehamilan sedangkan 3 ibu hamil mengetahui tentang perubahan psikologis selama kehamilan. Berdasarkan uraian di atas, peneliti tertarik untuk melakukan penelitian dengan judul "Gambaran Pengetahuan Ibu Hamil Tentang Perubahan Psikologis Selama Kehamilan di PMB Dyah Sugiyanto Surakarta Tahun 2019.”

\section{METODE PENELITIAN}

Penelitian ini merupakan penelitian deskriptif analitik dengan pendekatan cross sectional. Populasi penelitian ini adalah semua ibu hamil yang berkunjung di BPM Dyah Sugiyanto pada bulan Desember 2018 sebanyak 300 orang. Teknik penengambilan sampel pada penelitian ini menggunakan accidental sampling. Sampel dalam penelitian ini adalah sebagian dari ibu hamil yang memeriksakan kehamilan yang ditemui saat dilakukan penelitian di BPM Dyah Sugiyanto pada bulan Januari 2019 yaitu sebanyak 36 orang. Pada penelitian ini menggunakan alat pengumpul data berupa kuesioner, jenis kuesioner dalam penelitian ini adalah kuesioner tertutup dengan skala Guttman. Metode pengumpulan data yang digunakan adalah pengumpulan data primer dan sekunder. Dalam penelitian ini pengumpulan data primer dilakukan dengan membagikan kuesioner secara langsung kepada ibu hamil, sedangkan pengumpulan data sekunder dilakukan 
dengan cara melihat dokumen-dokumen atau catatan-catatan yang mendukung data penelitian. Analisa data dalam penelitian ini menggunakan distribusi frekuensi.

\section{HASIL DAN PEMBAHASAN}

Tabel 1 Distribusi Frekwensi Pengetahuan Ibu Hamil Tentang Perubahan Psikologis Selama Kehamilan di Praktik Mandiri Bidan Dyah Sugiyanto Tahun 2019.

\begin{tabular}{lccc}
\hline & Kategori & Frekuensi (f) & Prosentase (\%) \\
\hline Baik D & 0 & 0 \\
a Cukup & 29 & 80,55 \\
r Kurang & 7 & 19,44 \\
i Jumlah & 36 & 100 \\
\hline
\end{tabular}

Berdasarkan tabel 1 menunjukan bahwa gambaran pengetahuan responden tentang perubahan psikologis selama kehamilan sebagian besar masuk dalam kategori cukup yaitu sebanyak 29 responden $(80,55 \%)$.

Tabel 2 Distribusi frekuensi Karakteristik Ibu di Praktik Mandiri Bidan Dyah Sugiyanto Tahun 2019.

\begin{tabular}{lcc}
\hline \multicolumn{1}{c}{ Karakteristik } & Frekuensi (f) & Prosentase (\%) \\
\hline Umur & & \\
16-20 tahun & 7 & 19,44 \\
$21-25$ tahun & 11 & 30,55 \\
$26-30$ tahun & 10 & 27,77 \\
31-35 tahun & 8 & 22,22 \\
Total & 36 & 100 \\
Pendidikan & & \\
SD & 7 & 19,44 \\
SMP & 14 & 38,88 \\
SMA & 10 & 27,77 \\
PT & 5 & 13,88 \\
Total & 36 & 100 \\
Pekerjaan & & \\
IRT & 9 & 25 \\
Buruh & 11 & 30,55 \\
Swasta & 13 & 36,11 \\
PNS & 3 & 8,33 \\
Total & 36 & 100 \\
\hline
\end{tabular}

Dari tabel 2 diatas menunjukan bahwa sebagian besar karakteristik responden berumur 21-25 tahun sebanyak 11 responden (30,55\%). Karakteristik responden berdasarkan pendidikan formal sebagian besar dengan pendidikan terakhir SMP sebanyak 14 responden (38,88\%). Karakteristik responden berdasarkan pekerjaan sebagian besar swasta sebanyak 13 responden $(36,11 \%)$. 
Tabel 3 Distribusi Frekuensi Pengetahuan Ibu Hamil Tentang Perubahan Psikologis Selama Kehamilan di Praktik Mandiri Bidan Dyah Sugiyanto Tahun 2019 Berdasarkan Karakteristik Responden.

\begin{tabular}{|c|c|c|c|c|c|c|c|c|}
\hline \multirow{3}{*}{ Karakteristik } & \multicolumn{6}{|c|}{ Tingkat Pengetahuan } & \multirow{2}{*}{\multicolumn{2}{|c|}{ Responden }} \\
\hline & \multicolumn{2}{|c|}{ Baik } & \multicolumn{2}{|c|}{ Cukup } & \multicolumn{2}{|c|}{ Kurang } & & \\
\hline & $\mathbf{F}$ & $\%$ & $\mathbf{F}$ & $\%$ & $\mathbf{F}$ & $\%$ & $\sum$ & $\%$ \\
\hline \multicolumn{9}{|l|}{ Umur } \\
\hline $16-20$ & 0 & 0 & 6 & 16,66 & 1 & 2,77 & 7 & 19,44 \\
\hline $21-25$ & 0 & 0 & 9 & 25 & 2 & 5,55 & 11 & 30,55 \\
\hline $26-30$ & 0 & 0 & 6 & 16,66 & 4 & 11,11 & 10 & 27,77 \\
\hline $31-35$ & 0 & 0 & 8 & 22,22 & 0 & 0 & 8 & 22,22 \\
\hline Jumlah & 0 & 0 & 29 & 80,54 & 7 & 19,43 & 36 & 100 \\
\hline \multicolumn{9}{|l|}{ Pendidikan } \\
\hline SD & 0 & 0 & 7 & 19,44 & 0 & 0 & 14 & 38,88 \\
\hline SMP & 0 & 0 & 10 & 27,77 & 4 & 11,11 & 14 & 38,88 \\
\hline SMA & 0 & 0 & 9 & 25 & 1 & 2,77 & 10 & 27,77 \\
\hline PT & 0 & 0 & 3 & 8,33 & 2 & 5,55 & 5 & 13,88 \\
\hline Jumlah & 0 & 0 & 29 & 80,54 & 7 & 19,44 & 36 & 100 \\
\hline \multicolumn{9}{|l|}{ Pekerjaan } \\
\hline IRT & 0 & 0 & 8 & 22,22 & 1 & 2,77 & 9 & 25 \\
\hline Buruh & 0 & 0 & 9 & 25 & 2 & 5,55 & 11 & 30,55 \\
\hline Swasta & 0 & 0 & 9 & 25 & 4 & 11,11 & 13 & 36,11 \\
\hline PNS & 0 & 0 & 2 & 5,55 & 1 & 2,77 & 3 & 8,33 \\
\hline Jumlah & 0 & 10 & 28 & 77,77 & 8 & 22,22 & 36 & 100 \\
\hline
\end{tabular}

Berdasarkan tabel 3 menunjukkan bahwa sebagian besar pengetahuan ibu hamil tentang perubahan psikologis selama kehamilan berdasarkan karakteristik umur sebagian besar dengan kategori cukup pada umur 21-25 tahun sebanyak 9 responden $(25 \%)$. Pengetahuan ibu hamil tentang perubahan psikologis selama kehamilan berdasarkan pendidikan sebagian besar dengan kategori cukup dengan pendidikan formal SMP sebanyak 10 responden $(27,77 \%)$. Pengetahuan ibu hamil tentang perubahan psikologis selama kehamilan berdasarkan pekerjaan sebagian besar dengan kategori cukup dengan buruh dan swasta sebanyak 9 responden $(25 \%)$ dan sebanyak 9 responden $(25 \%)$.

Berdasarkan tabel 1 pengetahuan ibu hamil tentang perubahan psikologis selama kehamilan di BPM Dyah Sugiyanto Tahun 2014 sebanyak 36 responden, sebagian besar mempunyai pengetahuan cukup yaitu sebanyak 29 responden $(80,55 \%)$, dikarenakan umur yang sudah matang diatas 20 tahunan, pendidikannya menengah.

Pengetahuan merupakan hasil tahu, dan terjadi setelah orang melakukan pengindraan terhadap suatu obyek tertentu. Pengindraan terjadi melalui pancaindra manusia yakni: indra penglihatan, pendengaran, penciuman, rasa dan raba. Pengindraan tersebut dipengaruhi oleh intensitas perhatian persepsi terhadap obyek mencapai pengetahuan.(Notoatmodjo,S.,2007).Semakin tinggi pengetahuan ibu maka ibu akan lebih mengetahui tentang apa itu kehamilan dan hal hal yang mengenai perubahan psikologis selama kehamilan sehingga ibu mampu mengatasi maupun memantau perubahan perubahan yang terjadi pada dirinya, ibu yang memiliki pengetahuan yang kurang maka akan mempengaruhi keadaannya karena ibu tidak mengerti bagaimana perubahan psikologis sehingga dia hanya akan 
fokus pada dirinya dan apa yang terjadi pada dirinya. Pada penelitian ini di dapatkan mayoritas ibu hamil berpengetahuan cukup yaitu sebanyak 29 responden $(80,55 \%)$, karena semakin cukup usia tingkat kematangan dan kekuatan seseorang akan lebih matang dalam berpikir dan bekerja. Hal ini sebagai akibat dari pengalaman dan kematangan jiwanya, kemampuan berpikir kreatif mencapai puncaknya dalam usia dua puluhan.(Diana, 2013)

Faktor-Faktor yang mempengaruhi pengetahuan, Umur ibu yang muda mempengaruhi pengetahuan ibu karena umur ibu yang muda maka pola pikir ibu juga lebih luas dan lebih menerima gagasan gagasan atau informasi dari luar dari media massa, elektronik maupun dari tetangga atau saudara, biasanya terjadi pada umur dua puluhan. Pendidikan juga mempengaruhi pengetahuan semakin tinggi pengetahuan ibu tentang kehamilannya, namun faktor pendidikan juga tidak mempengaruhi pengetahuan bisa saja ibu tidak mempelajari hal hal tentang kehamilan dan tidak peduli dengan hal hal yang terjadi pada kehamilan. Pekerjaan sebagian besar ibu hamil buruh dan swasta, sehingga mempunyai peluang lebih banyak untuk memperoleh pengetahuan tentang perubahan psikologis selama kehamilan dari pada responden yang bekerja sebagai pegawai negeri. (Notoatmodjo,S.,2007).

Pada penelitian ini di dapatkan ibu hamil berpengetahuan kurang yaitu sebanyak 7 responden $(19,44 \%)$, kemungkinan hal ini terjadi karena kurang mengertinya tentang perubahan psikologis selama kehamilan. Faktor-Faktor yang mempengaruhi pengetahuan, Umur ibu yang terlalu muda mempengaruhi pengetahuan ibu karena umur ibu yang terlalu muda maka pola pikir ibu juga belum luas dan sulit menerima gagasan gagasan atau informasi dari luar dari media massa, elektronik maupun dari tetangga atau saudara, biasanya terjadi pada umur dibawah dua puluhan. Pendidikan yang tinggi bukan berarti pengetahuan ibu tentang kehamilannya juga tinggi, bisa saja ibu tidak mempelajari hal hal tentang kehamilan dan tidak peduli dengan hal hal yang terjadi pada kehamilan. Pekerjaan yang tingkat fleksibilitas kerja tinggi bukan berarti ibu mempunyai pengetahuan yang tinggi pula, bisa saja ibu tidak memiliki waktu luang untuk mempelajari hal hal tentang kehamilan dan tidak peduli dengan hal hal yang terjadi pada kehamilan.(Primasari, 2010).

Karakteristik ibu hamil tentang perubahan psikologis selama kehamilan. Faktor-faktor yang mempengaruhi pengetahuan, antara lain umur, pendidikan, dan pekerjaan. Umur adalah variabel yang sudah diperhatikan dalam penyelidikan epidemiologi, yaitu pada angka kesulitan ataupun angka kematian, pada tabel diatas menunjukan bahwa sebagian besar karakteristik responden berumur 21-25 tahun sebanyak 11 responden (30,55\%). Semakin cukup usia tingkat kematangan dan kekuatan seseorang akan lebih matang dalam berpikir dan bekerja. Hal ini sebagai akibat dari pengalaman dan kematangan jiwanya, kemampuan berpikir kreatif mencapai puncaknya dalam usia dua puluhan.(Diana, 2013)

Pendidikan adalah suatu proses pembentukan kecepatan seseorang secara intelektual dan emosional ke arah alam dan sesama manusia, pada tabel diatas menunjukan bahwa sebagian besar karakteristik responden berdasarkan pendidikan formal sebagian besar dengan pendidikan terakhir SMP sebanyak 14 responden $(38,88 \%)$. Pendidikan dapat mempengaruhi seseorang untuk 
mendapatkan informasi baik dari orang lain maupun dari media massa Semakin tinggi pendidikan semakin tinggi pula pengetahuannya.(Wawan, 2011).

Pekerjaan merupakan suatu kegiatan atau aktivitas seseorang untuk memperoleh penghasilan guna memenuhi kebutuhan hidup sehari-hari. Pekerjaan yang dikembangkan memberikan pengetahuan dan ketrampilan profesional serta pengalaman belajar selama bekerja akan dapat mengembangkan kemampuan mengambil keputusan merupakan manifestasi dari keterpaduan menalar secara ilmiah dan etik yang bertolak dari masalah nyata dalam bidang kerjanya, pada tabel diatas menunjukan bahwa sebagian besar karakteristik responden berdasarkan pekerjaan sebagian besar swasta sebanyak 13 responden $(36,11 \%)$.

Pengetahuan sangat erat kaitannya dengan pendidikan dimana diharapkan seseorang dengan pendidikan tinggi, maka orang tersebut semakin luas pula. Pengetahuan tidak mutlak diperoleh melalui pendidikan formal meliputi tingkat dasar (SD), menengah (SMP, SMA), dan tingkat perguruan tinggi (Akademi, PT)

Berdasarkan tabel 3 menujukkan bahwa pengetahuan ibu hamil tentang perubahan psikologis selama kehamilan berdasarkan karakteristik yaitu sebagian besar mempunyai pengetahuan yang cukup pada umur 21-25 tahun yaitu sebanyak 9 responden $(25 \%)$. Hal ini sesuai dengan teori bahwa semakin cukup umur maka semakin tinggi tingkat kematangan dan kekuatan seseorang sehingga cara berfikir dan bekerja seseorang semakin optimal. Kepercayaan masyarakat terhadap seseorang yang lebih dewasa akan meningkat. (Fariza, 2013)

Pengetahuan ibu hamil berdasarkan karakteristik pendidikan yaitu hasil paling dominan mempunyai pengetahuan yang cukup pada SMP sebanyak 10 responden $(27,77 \%)$. Hal ini sesuai dengan teori, pengetahuan sangat erat kaitannya dengan pendidikan dimana diharapkan seseorang dengan pendidikan tinggi, maka orang tersebut semakin luas pula pengetahuannya, namun perlu di tekankan bahwa seorang dengan pendidikan rendah tidak berarti mutlak berpengetahuan rendah pula. Pengetahuan tidak mutlak diperoleh melalui pendidikan formal meliputi tingkat dasar (SD), menengah (SMP, SMA), dan tingkat perguruan tinggi (Akademi, PT). (Fariza, 2013).

Pengetahuan berdasarkan karakteristik pekerjaan ibu hamil sebagian besar mempunyai pengetahuan cukup pada buruh dan swasta sebanyak 9 responden (25\%) dan 9 responden (25\%). Hal ini sesuai dengan teori, pekerjaan bukanlah sumber kesenangan, tetapi lebih banyak merupakan cara mencari nafkah yang membosankan, berulang dan banyak tantangan. Sedangkan pekerjaan umumnya merupakan kegiatan yang menyita waktu, sehingga juga dapat berpengaruh pada pengetahuan. (Diana, 2013)

\section{SIMPULAN DAN SARAN}

\section{Simpulan}

Pengetahuan ibu hamil tentang perubahan psikologis selama kehamilan di PMB Dyah Sugiyanto Tahun 2019 pengetahuan cukup sebanyak 29 responden $(80,55 \%)$. Pengetahuan ibu hamil tentang perubahan psikologis selama kehamilan berdasarkan karakteristik, mayoritas responden berpengetahuan cukup pada usia 21-25 tahun sebanyak 9 responden (25\%). Pengetahuan responden tentang 
perubahan psikologis selama kehamilan berdasarkan karakteristik, mayoritas responden berpengetahuan cukup pada responden yang memiliki pendidikan SMP sebanyak $10 \mathrm{ibu}$ hamil $(27,7 \%)$. Pengetahuan responden tentang perubahan psikologis selama kehamilan berdasarkan karakteristik, mayoritas responden berpengetahuan cukup pada responden yang bekerja sebagai swasta sebanyak 9 ibu hamil (25\%).

\section{Saran}

Bagi ibu hamil hendaknya menambah pengetahuannya tentang perubahan psikologis selama kehamilan dari sumber manapun yang dapat dipercaya kebenarannya seperti dari internet atau konseling kepada bidan ataupun tenaga kesehatan lainnya. Bagi tenaga kesehatan khususnya bidan dapat lebih aktif dalam memberikan pendidikan kesehatan kepada ibu hamil tentang perubahan psikologis ibu hamil, terutama yang berpendidikan sekolah dasar.

\section{DAFTAR PUSTAKA}

Diana Nur Arisnawati, 2013. Tingkat pengetahuan ibu hamil trimester III Tentang adaptasi psikologi masa nifas di RB Marga Waluya Surakarta Tahun 2013. Karya tulis ilmiah, Stikes Kusuma Husada Surakarta .

Fariza. A. 2013. Hubungan Status Gizi Dengan Tingkat Sosial Ekonomi Orang Tua / Wali Murid Siswa Kelas Atas Sekolah Dasar Negeri 3 Jatiluhur Kecamatan Karanganyar Kabupaten Kebumen. Skripsi Fakultas Ilmu Keolahragaan Universitas Negeri Yogyakarta .

Kusmiyati Y, Dkk. 2008. Perawatan Ibu Hamil. Cetakan ke VI. Yogyakarta :Fitramaya.

Laily Yuliatun, 2011.Perbedaan Tingkat Kecemasan Dalam Menghadapi Persalinan Pada Ibu Yang Rutin Dan Tidak Rutin Melakukan Kunjungan Ante Natal Care (ANC) Di Puskesmas Dinoyo Kota Malang.

Mandriwati, Dra. 2007. Penuntun Belajar Asuhan Kesehatan Ibu Hamil. Jakarta : EGC.

Maulana HDJ. 2007. Promosi Kesehatan. Jakarta: EGC Jakarta.

Ngalim Purwanto, 2011. Psikologi pendidikan PT. Remaja Rosdakarya : Bandung

Notoatmodjo, S. 2007. Promosi Kesehatan \& Ilmu Perilaku. Rineka Cipta : Jakarta

Primasari, Angeline Melinda, 2010, Perilaku Kesehatan Ibu Hamil di Indonesia (Analisis SDKI 2007), Skripsi, Yogyakarta : Fakultas Geografi Universitas Gadjah Mada.

Saifuddin, Abdul. (2008). "Pelayanan Kesehatan Maternal Dan Neonatal". Jakarta : Yayasan Bina Pustaka.

Sulistyowati, A. 2009. Asuhan Kebidanan Pada Masa Kehamilan. Jakarta : Salemba Medika

Wawan, A dan Dewi, M. 2011. Pengetahuan Sikap dan Perilaku Manusia. Yogyakarta: Nuha Medika 